\title{
Using Learning Objectives for Course Design and Curriculum Improvement
}

\author{
Donald D. Carpenter \\ Civil Engineering Department \\ Lawrence Technological University, Southfield, MI 48075
}

\begin{abstract}
Learning Objectives are statements of specific observable actions a student should be able to perform after an established period of time (a lecture, course, or curriculum). Learning Objectives, which are also commonly referred to as Instructional, Teaching, or Educational Objectives, clarify the expectations of faculty in terms of measurable or observable student performance. In other words, these statements describe the ability of students to demonstrate they have indeed learned what was expected of them. As such, learning objectives are a powerful tool for course design and curriculum improvement. Learning objectives can be used for course design by identifying critical material, facilitating course activities, writing examinations, and maximizing student learning. Learning objectives can be used for curriculum improvement by communicating course expectations to faculty and students, organizing key points of learning throughout the curriculum, eliminating excessive duplication of material, and providing assessment of course performance. However, if objectives are not sufficiently well defined, both testing and assessment based on those objectives are unlikely to be effective in determining if students have mastered the required topic. This paper and associated presentation will describe learning objectives in detail and provide assistance on how to effectively write and implement objectives. The goal is to assist new engineering educators in designing their courses, communicating information to their students and fellow faculty, and focusing their instruction on student learning as opposed to teaching.
\end{abstract}

\section{Introduction}

Learning Objectives are statements of specific observable outcomes a student should be able to perform after a period of time. They are also commonly referred to as Instructional, Teaching, or Educational Objectives. Typically, a learning objective has the form ${ }^{5}$ :

Upon completion of this [course, chapter, week, lecture], you should be able to [calculate, solve, estimate, describe, design] the ...,

Proceedings of the 2005 American Society for Engineering Education Annual Conference and Exposition Copyright (C) 2005, American Society for Engineering Education 
where the first bracket item is a timeframe and the second bracket item is an action verb. Some examples of learning objectives include:

At the end of this unit, you should be able to calculate velocity in a closed conduit using Darcy-Weisbach and Hazen-Williams equations.

At the end of this class, you should be able describe the function of the kidney in removing toxins from the human body.

At the end of this course, you should be able to generate a business plan for a start-up company that would support a request for venture capital.

Well-written objectives clarify the expectations of the instructor in terms of measurable or observable student performance. As such, objectives can play a key role in the educational process. A set of published learning objectives can provide a focus for instruction, facilitate course activities, communicate expectations to students and to other faculty, and provide targets for assessment ${ }^{1,2}$.

\section{Writing Learning Objectives}

Consider the following objective:

At the end of the course, I should instill upon the student a comprehension of the design process.

This objective has several problems. First, by using the first person and the verb "instill", the objective is teacher focused and not student focused. Learning objectives should be statements of measurable student performance. A rewrite of the objective to make it student focused would read:

At the end of the course, you should comprehend the design process.

While improved, this objective uses the verb "comprehend.” While student comprehension is desirable, it is not a measurable outcome. When writing learning objectives, verbs such as "comprehend", "understand" or "know" should be avoided because they are not directly observable student actions. Hence, action verbs used for teaching objectives should be measurable, observable, definable, and understandable. Another rewrite using an appropriate action verb yields an acceptable learning objective:

At the end of the course, a student should be able to apply the design process.

However, this learning objective is vague. An individual reading this objective would not be able to identify the course associated with this objective. Vague and poorly written objectives do 
not convey clear expectations and make student learning harder to assess. A final draft clearly conveys expectations:

At the end of the course, the student should be able to apply the design process for completion of a directional freeway interchange following AASHTO guidelines.

This is still a very broad learning objective, but it represents a course objective for a course in highway engineering. An instructor could write numerous unit or lecture learning objectives that support this course objective. The objective might be improved by removing the acronym AASHTO and spelling out American Association of State Highway and Transportation Officials, but student enrolling in a senior level highway engineering course would be familiar with this acronym. The use of acronyms or abbreviation in learning objectives is acceptable, but the writer should consider the audience.

When determining which action verb is appropriate to use in an objective, thought should be given to the different levels of learning/performance and how the verb can be applied to the different domains. For example, according to Bloom's Taxonomy, the cognitive domain has six defined levels (knowledge, comprehension, application, analysis, synthesis, and evaluation) ${ }^{3}$. The first three levels are considered lower level thinking skills while the second three are considered higher level thinking skills. Samples of action verbs based on these levels can be found in Table 1 which was modified from Bloom and Krathwohl ${ }^{3}$. The cognitive domain is the domain commonly dealt with in engineering courses, however, the affective domain can be important too, especially for the "softer" skills acquired for accreditation. Samples of action verbs based on the affective domain can be found in Table 2 which was modified from Krathwohl et $\mathrm{al}^{4}$.

Table 1: Action Verbs for the Cognitive Domain (Intellectual Outcomes)

\begin{tabular}{|c|c|}
\hline Level & Action Verbs \\
\hline Knowledge & $\begin{array}{l}\text { define, describe, identify, label, list, match, outline, } \\
\text { reproduce, select, state }\end{array}$ \\
\hline Comprehension & $\begin{array}{l}\text { convert, defend, distinguish, estimate, explain, extend, } \\
\text { generalize, give example, infer, paraphrase, predict, } \\
\text { rewrite, summarize }\end{array}$ \\
\hline Application & $\begin{array}{l}\text { change, compute, demonstrate, discover, manipulate, } \\
\text { modify, operate, predict, prepare, produce, relate, show, } \\
\text { solve, use }\end{array}$ \\
\hline Analysis & $\begin{array}{l}\text { break down, differentiate, discriminate, distinguish, } \\
\text { identify, illustrate, infer, outline, point out, relate, select, } \\
\text { separate, subdivide }\end{array}$ \\
\hline Synthesis & $\begin{array}{l}\text { categorize, combine, compile, compose, create, devise, } \\
\text { design, explain, generate, modify, organize, plan, } \\
\text { rearrange, revise, rewrite, summarize, tell, write }\end{array}$ \\
\hline Evaluation & $\begin{array}{l}\text { Appraise, compare, conclude, contrast, criticize, support, } \\
\text { discriminate, explain, justify, interpret, relate, summarize }\end{array}$ \\
\hline
\end{tabular}

Proceedings of the 2005 American Society for Engineering Education Annual Conference and Exposition Copyright (C) 2005, American Society for Engineering Education 
Table 2: Action Verbs for the Affective Domain (Emotional Outcomes)

\begin{tabular}{|c|c|}
\hline Level & Action Verbs \\
\hline Receiving & $\begin{array}{l}\text { ask, choose, describe, follow, give, hold, identify, locate, } \\
\text { name, point to, select, reply, use }\end{array}$ \\
\hline Responding & $\begin{array}{l}\text { answer, assist, compile, conform, discuss, greet, help, } \\
\text { label, perform, practice, present, read, recite, report, } \\
\text { select, tell, write }\end{array}$ \\
\hline Valuing & $\begin{array}{l}\text { complete, describe, differentiate, explain, follow, form, } \\
\text { initiate, invite, join, justify, propose, read, report, select, } \\
\text { share, study, work }\end{array}$ \\
\hline Organization & $\begin{array}{l}\text { adhere, alter, arrange, combine, compare, complete, } \\
\text { defend, explain, generalize, identify, integrate, modify, } \\
\text { order, organize, prepare, relate, synthesize }\end{array}$ \\
\hline Characterization & $\begin{array}{l}\text { categorize, combine, compile, compose, create, devise, } \\
\text { design, explain, generate, modify, organize, plan, } \\
\text { rearrange, revise, rewrite, summarize, tell, write }\end{array}$ \\
\hline
\end{tabular}

\section{Using Learning Objectives}

As previously noted, learning objectives clarify the expectations of the instructor in terms of measurable or observable student performance. As such, objectives can play a key role in the educational process and can serve many functions including providing guidelines for student learning, facilitating course activities, assessing student learning, communicating instructional content to others, and evaluating instructional methods ${ }^{1,2}$.

\section{Using learning objectives to provide a guide for student learning}

This represents the most obvious and important role for learning objectives. Objectives communicate expectations for the semester to the students. They will be aware not only of topical coverage, but of what they will learn and be able to achieve. This involves the students in the learning process and provides them a guide for what they are expected to accomplish. Informing students of the intended outcomes at the beginning of a course will provide not only direction for their learning, but also a basis for self evaluation of their progress. It can also be advantageous for instructors to periodically review the course learning objectives with the students. This will aid students in determining where the instructor is and where he is going in a course. In the end, the students will have a better understanding of course content and will likely retain more information if they periodically reflect upon their accomplishments. Arguably, one of the distinctions between educated individuals and those that are merely trained is that educated individuals possess the ability to reflect on their goals, and how they have or have not met them. Finally, mastery of the course objectives will undoubtedly result in a good grade (a goal for most students). 


\section{Using learning objectives to facilitate course activities}

Traditional methods of course planning and design typically focus on content, course materials (books, etc), and delivery method and not on how students will demonstrate what they have learned. Commonly, a new engineering educator might have received a sample syllabus and a copy of the text for the course. Blindly following what previous instructors of the course have done is obviously easier for a new instructor, but definitely not the best method for course development.

Alternatively, a course can be designed by first writing course learning objectives. Since objectives are statements of what we expect the students to accomplish, they can aid in selecting course materials and delivery methods to ensure student learning. They can also help an instructor prepare lectures, assignments, and examinations that focus on desired student outcomes. In addition to assisting in writing assignments and examinations, objectives can also be used by students to review course content and prepare for exams. Since the course is now focused on objectives, objectives can be used to check student learning and provide feedback to students as the course progresses. This allows the instructor to adapt methodologies during the semester as needed. Additionally, objectives can be used during course planning to streamline a course and delete superfluous material that does not support desired student outcomes.

Finally, course objectives can be extremely useful in helping students obtain higher order learning skills. Writing objectives that require higher order thinking and then planning course activities to address those outcomes drive students to become better thinkers and learners. Without learning objectives, it is quite possible an instructor may never require students to perform beyond comprehension and application.

\section{Using learning objectives to facilitate assessment of student learning}

Well-stated objectives make it clear to the students what they should be capable of, so exams, homework assignments, and in-class activities can all be developed accordingly. After all, it is only appropriate to assess student learning based on the objectives set before them. The type of assessment instrument (quiz, essay, etc.) utilized should vary depending on the objective. For example, if the action verb "explain" is used in an objective, an essay or oral assignment would be appropriate. If an objective was based on "solving" a problem, then a more traditional homework problem might suffice. Either way, objectives help clarify the criteria that will be used to assess performance. Finally, learning objectives can be used at the end of the term in conjunction with either direct or indirect assessment tools as part of program assessment.

\section{Using learning objectives to communicate instructional content}

Learning objectives are extremely conducive to communicating course content to both students and faculty. Writing and publicizing course learning objectives can give students a much better indication of course content compared to a one paragraph catalog description. Additionally, learning objectives inform students at the beginning of the course what they will be expected to

\footnotetext{
Proceedings of the 2005 American Society for Engineering Education Annual Conference and Exposition
} Copyright (C) 2005, American Society for Engineering Education 
accomplish as they progress through the course. This reduces the confusion about course content for students and, in the case of elective courses, might help them decide whether to enroll.

Course learning objectives also provide key information for faculty. Learning objectives from a prerequisite course will inform an instructor what the students were able to accomplish upon course completion. This provides a knowledge base for students entering subsequent courses. This eliminates the need for excessive review of previous material. Some review may still be required (and prudent) to refresh student memory, but if prerequisite material is unclear or "foreign" to students, then a problem might exist with prerequisite instruction.

Course objectives can also be used to convey material coverage expectations to adjunct faculty or new instructors. Referring back to course design, consider how much easier it would be for a new engineering educator to receive objectives for a course and not just a textbook. In fact, new instructors should inquire if course learning objectives have been developed for a course. If not, perhaps they could work with more senior faculty in developing the objectives for a course. This could also assist in establishing a mentoring relationship, which can be very helpful for new educators. While course objectives can vary from semester to semester, there should be some fundamental objectives associated with a course that are covered every semester regardless of instructor. This could be considered a "quality control" procedure to insure key material is covered.

Finally, if every course has published learning objectives, then objectives associated with program outcomes can be quickly evaluated for coverage. A review committee can determine if either excessive material coverage or coverage gaps exist in the curriculum. Hence, objectives can be used as a cornerstone for departmental assessment programs in preparation for accreditation. For example, the Accreditation Board for Engineering and Technology (ABET) requires an engineering program to have published Program Educational Objectives and Program Outcomes $^{5}$. These Program Outcomes can be viewed as curricular learning objectives. In support of these objectives, faculty can write course learning objectives as described above, with more specific objectives written for chapters, units, laboratories, or lectures (Figure 1).

As a specific example, the Civil Engineering and Mechanical Engineering Departments at Lawrence Technological University in Southfield, MI have implemented the use of course learning objectives as part of their ABET Accreditation Process. The author has conducted several workshops during the past several years to educate the faculty on the writing and usage of learning objectives. In addition, books have been placed on reserve for faculty reference $2,4,6$ ${ }^{10}$ along with relevant articles from the American Society of Engineering Education Annual Conference Proceedings, the Frontiers in Education Conference Proceedings (http://fie.engrng.pitt.edu/), and the Journal of Engineering Education. Both Departments have Curriculum Review Boards that have mapped course learning objectives with the published Program Outcomes to insure proper coverage of topics across the curriculum. For a more detailed example, a recently published article by Richard Felder and Rebecca Brent provides an excellent example of how learning objectives and corresponding assessment can be used to design and teach courses in preparation for ABET accreditation ${ }^{11}$.

Proceedings of the 2005 American Society for Engineering Education Annual Conference and Exposition Copyright (C) 2005, American Society for Engineering Education 


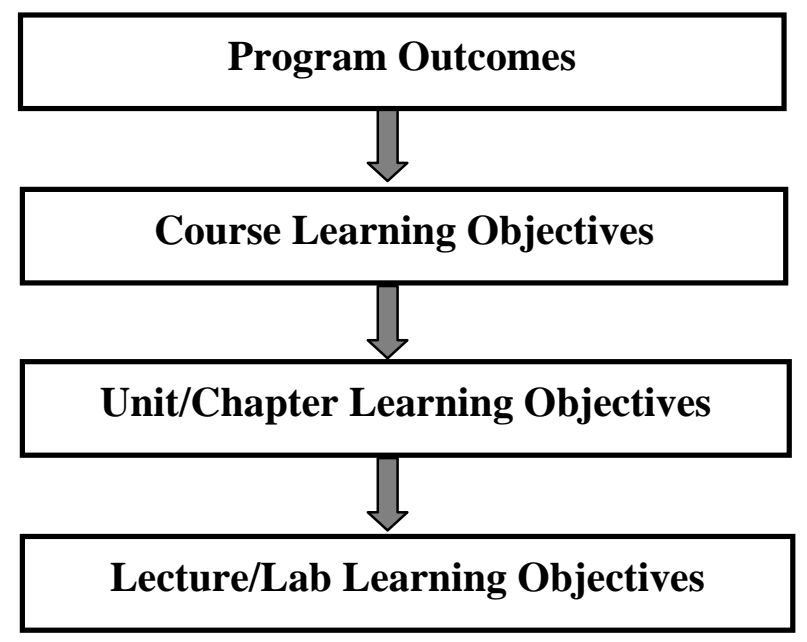

Figure 1: Structure for integrating Learning Objectives throughout the Curriculum

\section{$\underline{\text { Using learning objectives to evaluate instructional methods }}$}

Learning objectives can also be used to evaluate instructional methods. If students are unable to perform the objective as stated, it is possible the method of instruction utilized was inadequate. Conversely, if an entire class was able to perform an objective, the method of instruction was likely conducive to student learning. In some cases, the instruction might be fine but the objectives themselves or the assessment tool was inadequate. Whatever the case may be, learning objectives can provide a key diagnostic measurement.

\section{Summary}

Learning objectives are statements that describe the ability of students to demonstrate they have indeed learned what was expected of them. As such, learning objectives can play a key role in the educational process. New engineering educators can benefit greatly from their usage and the additional effort upfront in their development can help streamline other course activities. In addition to being valuable for course development, learning objectives can be used for course improvement by identifying critical material, facilitating course activities, and maximizing student learning. Learning objectives can be used for curriculum improvement by communicating course expectations to faculty and students, organizing key points of learning throughout the curriculum, eliminating excessive duplication of material, and providing assessment of course performance. Therefore, learning objectives can also be a cornerstone for assessment programs designed to meet accreditation criteria. 


\section{Acknowledgment}

The author would like to acknowledge Richard Felder and Rebecca Brent as initial inspiration for using and promoting learning objectives after completion of their Effective Teaching Workshop in March of $2000^{12}$.

\section{References}

1. Felder, R.M and R. Brent, "Objectively Speaking", Chemical Engineering Education, 31, 3, 1997, pp 178179.

2. Grunlund, N.E., How to Write and Use Instructional Objectives $6^{\text {th }}$ ed, Englewood Cliffs, NJ: PrenticeHall. 1995.

3. Bloom, B.S. and D.R. Krathwohl, Taxonomy of Educational Objectives. Handbook 1. Cognitive Domain. NY: Addison-Wesley. 1984.

4. Krathwohl, D.R., B.S. Bloom, and B.B. Massina. Taxonomy of Educational Objectives. Handbook 2. Affective Domain. NY: Addison-Wesley, 1984.

5. ABET Criteria for Evaluating Engineering Programs, http://www.abet.org/criteria.html.

6. Anderson L and D.R. Krathwohl, A Taxonomy for Learning, Teaching, and Assessing. NY: Longman. 2001.

7. Angelo, T.A. and K.P. Cross, Classroom Assessment Techniques: A Handbook for College Teachers $2^{\text {nd }}$ ed. San Francisco: Jossey-Bass. 1993.

8. Johnson, D.W., R.T. Johnson, and K.A. Smith, Active Learning: Cooperation in the College Classroom $2^{\text {nd }}$ ed. Edina, MN: Interaction Book Co, 1998.

9. McKeachie, W. Teaching Tips 10 $0^{\text {th }}$ ed. Boston, MA: Houghton Mifflin. 1999.

10. Wankat P.C. and F.S. Oreovicz. Teaching Engineering. NY: McGraw-Hill. 1993.

11. Felder, R.M. and R. Brent, "Designing and Teaching Courses to Satisfy the ABET Engineering Criteria", Journal of Engineering Education, 92, 1, 2003, pp 7-25.

12. Felder, R.M. and R. Brent, Effective Teaching: A Workshop, University of Michigan, Ann Arbor, MI, March 10-11 ${ }^{\text {th }}, 2000$.

\section{DONALD D. CARPENTER}

Dr. Carpenter is an Assistant Professor of Civil Engineering. Dr. Carpenter also serves as Chair of the Educational Innovation Collaborative at LTU and Coordinator of the Civil Engineering Assessment Program. He is actively involved in ASEE and serves as Faculty Advisor for the ASCE Student Chapter at LTU. His research interests involve academic integrity, assessment tools, urban stream restoration, and watershed processes. 